\title{
Oxidation Stability Control of Egyptian Base Stock Using Some Newly Azophenols II
}

\author{
"Doaa .I.Osman ${ }^{1}$, Maher.I.Nessim ${ }^{1}$, Ali A M El-Bassoussi and ${ }^{1}$, \\ Ashraf. M. Ashmawy ${ }^{2}$ \\ ${ }^{1}$ Analysis \& Evaluation Department, Egyptian Petroleum Research Institute, Cairo, Egypt \\ ${ }^{2}$ Chemistry Department, Faculty of Science, AL-Azhar University, Cairo, Egypt
}

\begin{abstract}
The oxidation stability of local base stock, delivered from Co-operative Petroleum Company. In the presence of two prepared Azo-compounds, namely 2-sec-butyl-4-[(4-methoxyphenyl)-diazenyl] phenol (I) and 2-sec-butyl-4-[(4-nitrophenyl) ${ }^{\left.-{ }^{-i a z e n y l}\right]}$ phenol (II) was studied. The structures of the prepared two compounds were carefully investigated via Elemental analysis, I.R., ${ }^{1} H$-NMR spectroscopy, and electron ionization mass spectroscopy (EI-MS). The oxidation reaction was tested using the change in Total Acid Number (TAN), Viscosity, and Infra-Red (IR) spectroscopy. The data showed that compound (I) is more efficient than compound (II). The Quantum chemical parameters such as highest occupied molecular orbital (HOMO), lowest unoccupied molecular orbital (LUMO) energy levels, energy gap (EHOMO-ELUMO), the dipole moment and charge densities were calculated. The theoretical calculations were in good agreement with experimental results.
\end{abstract}

Keywords: Azo-phenol, Base Stocks, Oxidation stability, Total Acid Number and Quantum chemical calculations.

\section{Introduction}

A lubricant is a substance introduced between two moving surfaces to primarily reduce friction, improve efficiency, and reduce wear [1]. A lubricant may also serve the function of dissolving or transporting foreign particles, carrying away contaminations and debris, preventing corrosion or rust, sealing clearances, and dissipating heat [1-3]. Base oils are the major components of lubricants, representing usually $85 \%$ or more of the formulation. These base oils are in general of mineral origin, they are produced from petroleum crude oil by various processing steps [4].

Mineral lubricating oils are used in present of air whereby oxidative chemical reactions can take place, So Additives are necessary to enhance aspects of a base oils performance and replace compounds which may have been lost in the refining of oil. Additives packages are typically present at around $10 \% \mathrm{w} / \mathrm{w}$ of Final application. Although additives of many differs types have been developed to need special lubrication needs, they are used to reduce the oxidation or thermal degradation of base oil. Also they reduce wear, minimize rust and corrosion, lessen the deposition of harmful deposits on lubricated parts and prevent destructive metal-tometal contact [5-7].Oxidation is one of the most important processes causing degradation of engine oils during service. Oil oxidation leads to formation of acidic products, insoluble materials, and sludge, depletion of additives, loss of dispersancy, increase of viscosity, etc. All of these undesirable changes are affected by other concurrent processes occurring in an operating engine such as thermal degradation, mechanochemical reactions, and metal catalysis [8]. Hence, antioxidant additives became highly required to decrease oil oxidation, with secondary effect of reducing corrosion of certain types of sensitive bearing materials [4]. Antioxidants act in two different ways by radical scavengers, and by inhibition of peroxides [6]. Three types of additives have been proved to be successful in controlling the degradation of lubricating oils; radical scavengers, and hydro peroxide decomposers, as well as synergistic mixtures of both of them. Thus, various classes of compounds have been used as antioxidant-additives, such as phenols [9], amines [10], and heterocyclic compounds [11-12] as well as synergistic mixtures of them and also azo compounds [13-14].

Quantum chemical methods have already proven to be very useful in determining the molecular structure as well as elucidating the electronic structure and reactivity [15]. Through, employing computational methodology [16] and a set of mathematical equations which are capable of representing accurately the chemical phenomenon under study $[17,8]$. The study of oxidation processes and their inhibition by organic Inhibitors is a very active field of research [19].Many researchers report that the inhibition effect mainly depends on some physicochemical and electronic properties of the organic inhibitor which relate to its functional groups, steric effects, electronic density of donor atoms, and orbital character of donating electrons [20-21]. The inhibiting mechanism is generally explained by the formation of a physically and/or chemically adsorbed film on the metal surface [22-23]. It is well known that organic compounds which act as inhibitors are rich in heteroatoms, such as sulphur, nitrogen, and oxygen [24-25]. These compounds and their derivatives are 
excellent oxidation inhibitors in a wide range of media and are selected essentially from empirical knowledge based on their macroscopic physicochemical properties. Recently, theoretical prediction of the efficiency of oxidation inhibitors has become very popular in parallel with the progress in computational hardware and the development of efficient algorithms which assisted the routine development of molecular quantum mechanical calculations [24].In the present work, new two azo- phenol derivatives have been prepared and evaluated as antioxidant for lubricating oil.

\section{Raw Material}

\section{Experimental}

\section{Base Stock Oil:}

Hydro finished base stock oil (HBS) sample was obtained from Co-operative Petroleum Company.

The Reagents:

All reagents purchased from Merck, Aldrich and Fluka chemical companies. They were of analytical grade and used without further purification.

\section{Preparation of additives (I and II) [26, 27]:} Diazotization:

A mixture of aniline derivatives (4-methoxyaniline, 4-nitroaniline) $(0.05 \mathrm{~mol})$ was dissolved in distilled water and $(0.05 \mathrm{~mol})$ of dilute hydrochloric acid. The mixture was cooled in ice bath to zero. Sodium nitrite $(0.05 \mathrm{~mol})$ was added drop wise while stirring. Maintaining the temperature from $0-5^{\circ} \mathrm{c}$, the resulting mixture was stirred for $1 \mathrm{~h}$

\section{Coupling:}

A solution of phenol of $(.05 \mathrm{~mol}$ phenol was dissolved in $(0.05 \mathrm{~mol}) \mathrm{NaOH}$ in $15 \mathrm{ml}$ of water, was cooled to $0-5^{\circ} \mathrm{c}$ in an ice bath. This solution was then gradually added to the prepared diazonium solution. The mixture was stirred for further $20 \mathrm{~min}$. The product was acidified by acetic acid. The product was filtered, washed with distilled water and recrystallized from acetic acid.

The main scheme of preparation is shown as follows.

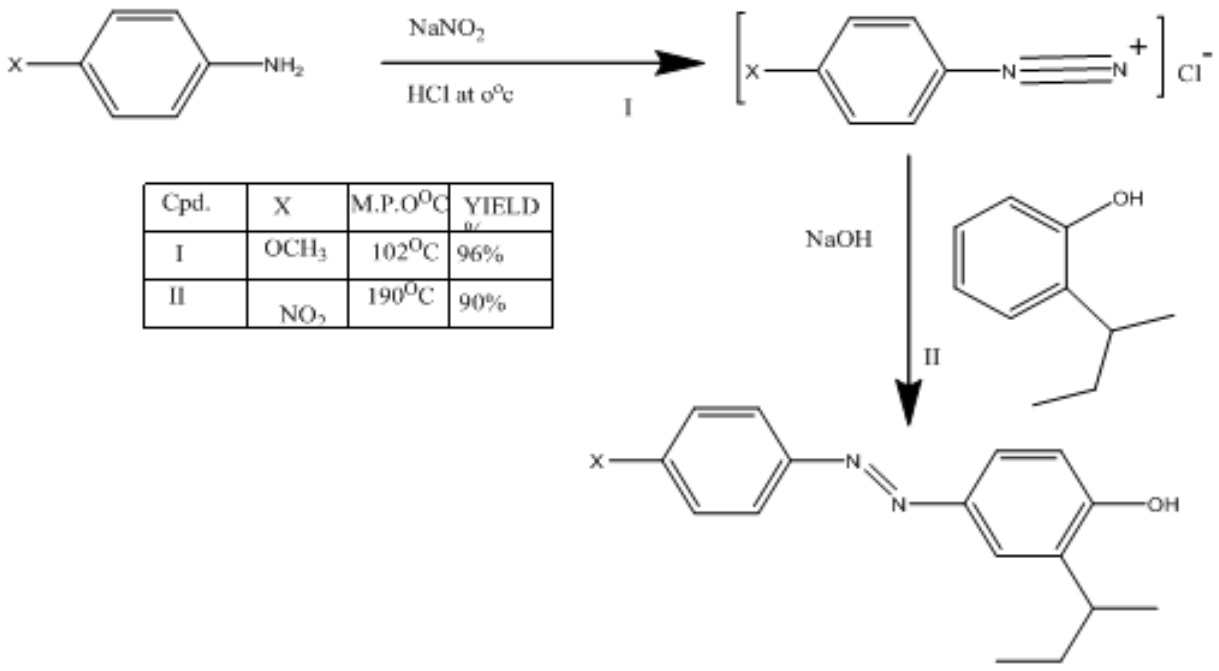

Scheme I

\section{Oxidation Stability Study}

The oxidation test was carried according to ASTMD-943 standard method. The operating temperature was changed to $120^{\circ} \mathrm{c}$ instead of $90^{\circ} \mathrm{c}$. The oxidation cell in the static mode contained $200 \mathrm{ml}$. base stocks, and activated copper and iron wires Catalysts. The base stock sample was subjected to oxidation with pure oxygen (99.95\%) at a flow rate of 0.1 liter/hour for maximum 96 hours. The characterized azo-phenol derivatives compounds (I-II) were added in different concentrations (200, 400 and $600 \mathrm{ppm}$ ). The oil sample after, 24, 48, 72 and 96 hours of oxidation time were analyzed for viscosity, total acid number and infra-red spectroscopy.

\section{Total Acid Number (Tan) And Viscosity}

Total acid number and viscosity were carried out according to ASTM standard test methods (D-664 and D- 445), respectively). 


\section{Ft-Ir Spectroscopy}

Infra-red spectra of the oxidized samples at different periods were recorded on FT-IR Spectrophotometer, Model 960M000g, ATI Mattson Infinity Series, USA. The spectra of the studied samples were measured in the range of $4000-400 \mathrm{~cm}^{-1}$ with a suitable scan resolution $4 \mathrm{~cm}$ and scan rate $32 \mathrm{~cm} / \mathrm{min}$. Elemental analyses were carried out in the Micro analytical Center, the center publication for research, Cairo, Egypt. By Elementary Viro El Microanalysis. ${ }^{1} \mathrm{HNMR}$ spectra recorded on a Varian $300 \mathrm{MHz}$ (Germany 1999) using TMS as internal standard (Cairo University). Mass spectroscopy was one using direct inlet unit (D1-50) of SHIMADZU GC/MS-QP5050A. At the regional center for mycology; AL-Azhar university.

\section{Results And Discussion}

The physicochemical properties of the base stock are carried out according to ASTM standard test methods. The results are tabulated in Table-(1)

Table (1) Show the physicochemical properties of the Base Stock:

\begin{tabular}{|c|c|c|}
\hline Test & RESULT & TEST METHOD \\
\hline Density @ $15.5^{\circ} \mathrm{C}, \mathrm{g} / \mathrm{L}$ & 0.8817 & ASTM D - 1298 \\
\hline Pour Point, ${ }^{\circ} \mathrm{C}$ & -6 & ASTM D - 97 \\
\hline Viscosity $\stackrel{@}{@} 100^{\circ} \mathrm{C}{ }^{\circ} \mathrm{C}$ & $\begin{array}{l}52.34 \\
7.41\end{array}$ & $\begin{array}{l}\text { ASTM D-445 } \\
\text { ASTM D-445 }\end{array}$ \\
\hline Viscosity Index (VI) & 92 & ASTM D - 2270 \\
\hline Total Acid Number (TAN) & 0.067 & ASTM D - 664 \\
\hline Sulfur Content, wt \% & 0.34 & ASTM D-4294 \\
\hline Color & 2.5 & ASTM D-1500 \\
\hline Ash Content, wt \% & 0.003 & ASTM D-482 \\
\hline Copper Corrosion & I a & ASTM D-130 \\
\hline Flash point, ${ }^{\circ} \mathrm{c}$ & 220 & ASTM D-92 \\
\hline Aniline point & 100.5 & ASTM D-611 \\
\hline Molecular Weight & 468.9 & \\
\hline
\end{tabular}

\section{Confirmation of the structures for I and II}

The structure of I and II is elucidated via the following tools of analysis:

Table (2): Elemental analysis of (I-II)

\begin{tabular}{|c|c|c|c|c|c|c|}
\hline Cpd. & \multicolumn{2}{|l|}{$\mathrm{C} \%$} & \multicolumn{2}{|l|}{ H\% } & \multicolumn{2}{|l|}{ N\% } \\
\hline \multirow[t]{2}{*}{ I } & Calc. & Obs. & Calc. & Obs. & Calc. & Obs. \\
\hline & 71.81 & 71.54 & 7.09 & 6.84 & 9.85 & 9.61 \\
\hline II & 64.95 & 63.96 & 6.41 & 5.01 & 13.37 & 13.69 \\
\hline
\end{tabular}

Table (3): Infra-Red spectra of I and II

\begin{tabular}{|l|l|l|l|l|l|l|l|}
\hline Cpd. & \multicolumn{9}{|c|}{ STREACHING OF, $\left(\boldsymbol{V}^{, \mathrm{cm}^{-1}}\right)$} \\
\hline & OH & CH $_{\text {aromatic }}$ & CH $_{\text {aliphatic }}$ & C=C & N=N & C-O-C & NO $_{2}$ \\
\hline & $3550-3415$ & 2962 & 2868 & 1584 & 1453 & 1251 & - \\
\hline & 3416 broad & 2961 & 2874 & 1593 & 1455 & - & 134 \\
\hline
\end{tabular}

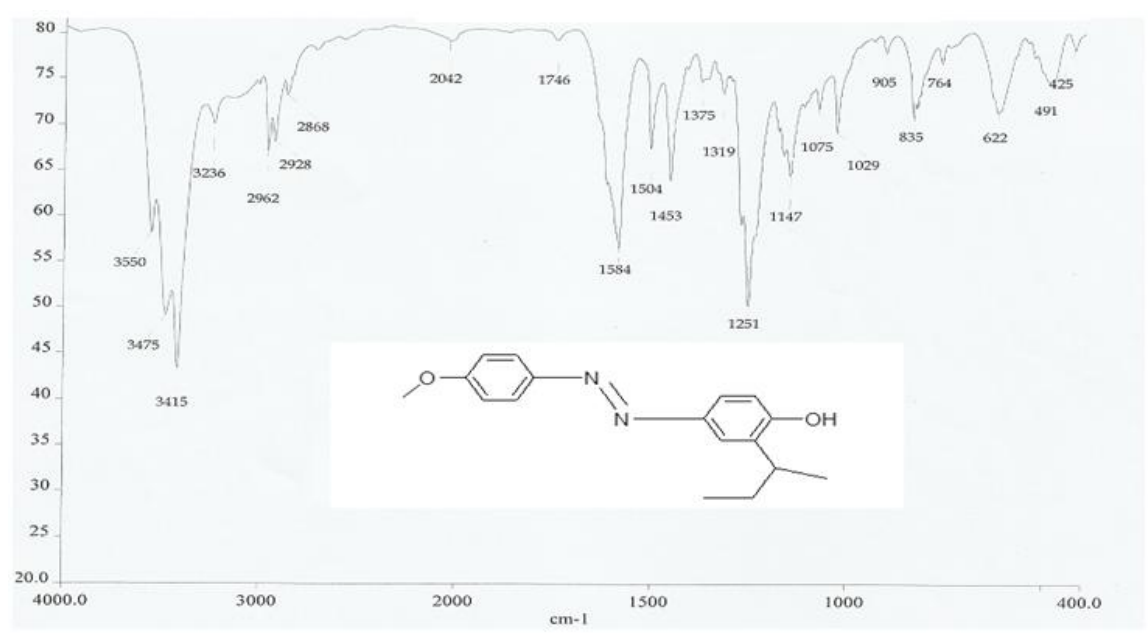

Fig. (1): Infrared spectrum of the prepared compound ( I). 


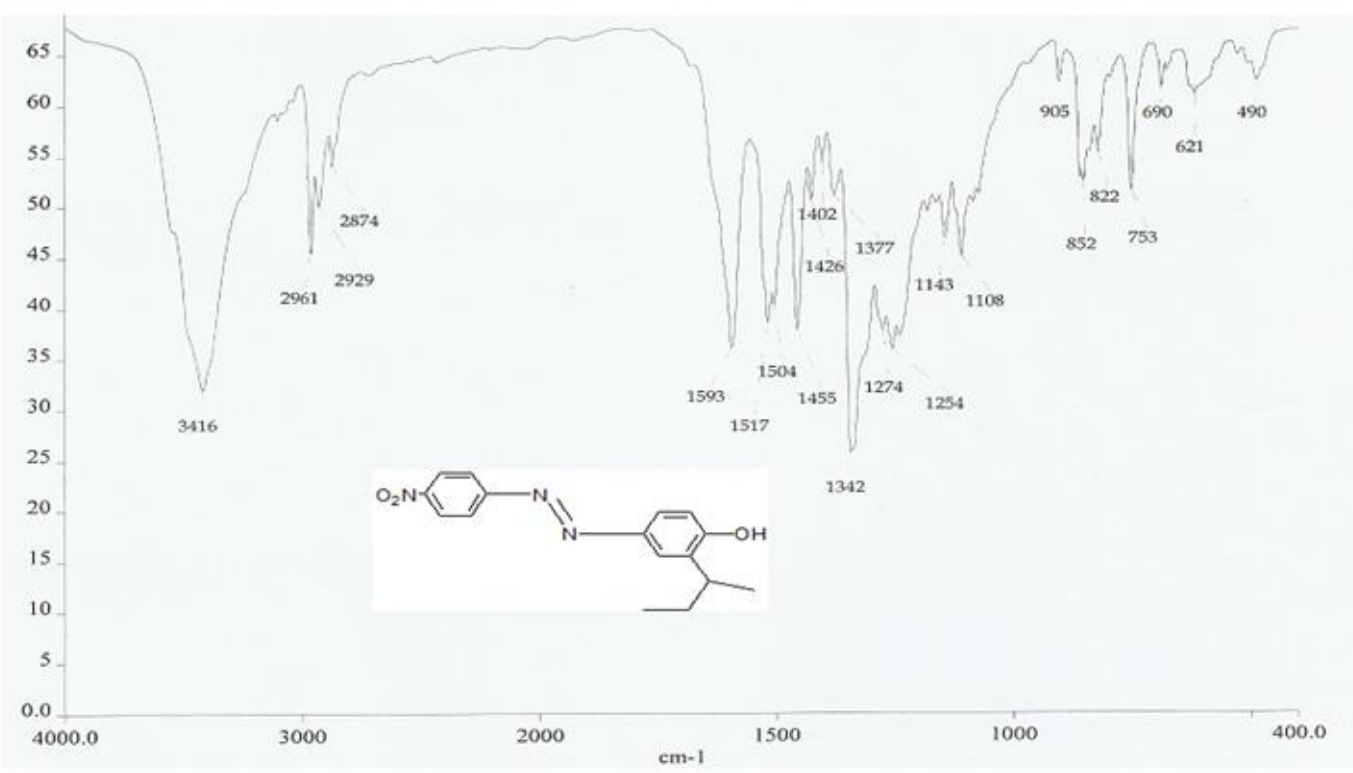

Fig. (2): Infrared spectrum of the prepared compound (II).

Table (3) Chemical Shifts of compound (I, II)

\begin{tabular}{|l|l|l|l|l|l|l|l|l|l|l|l|l|}
\hline I & & & \\
\hline
\end{tabular}

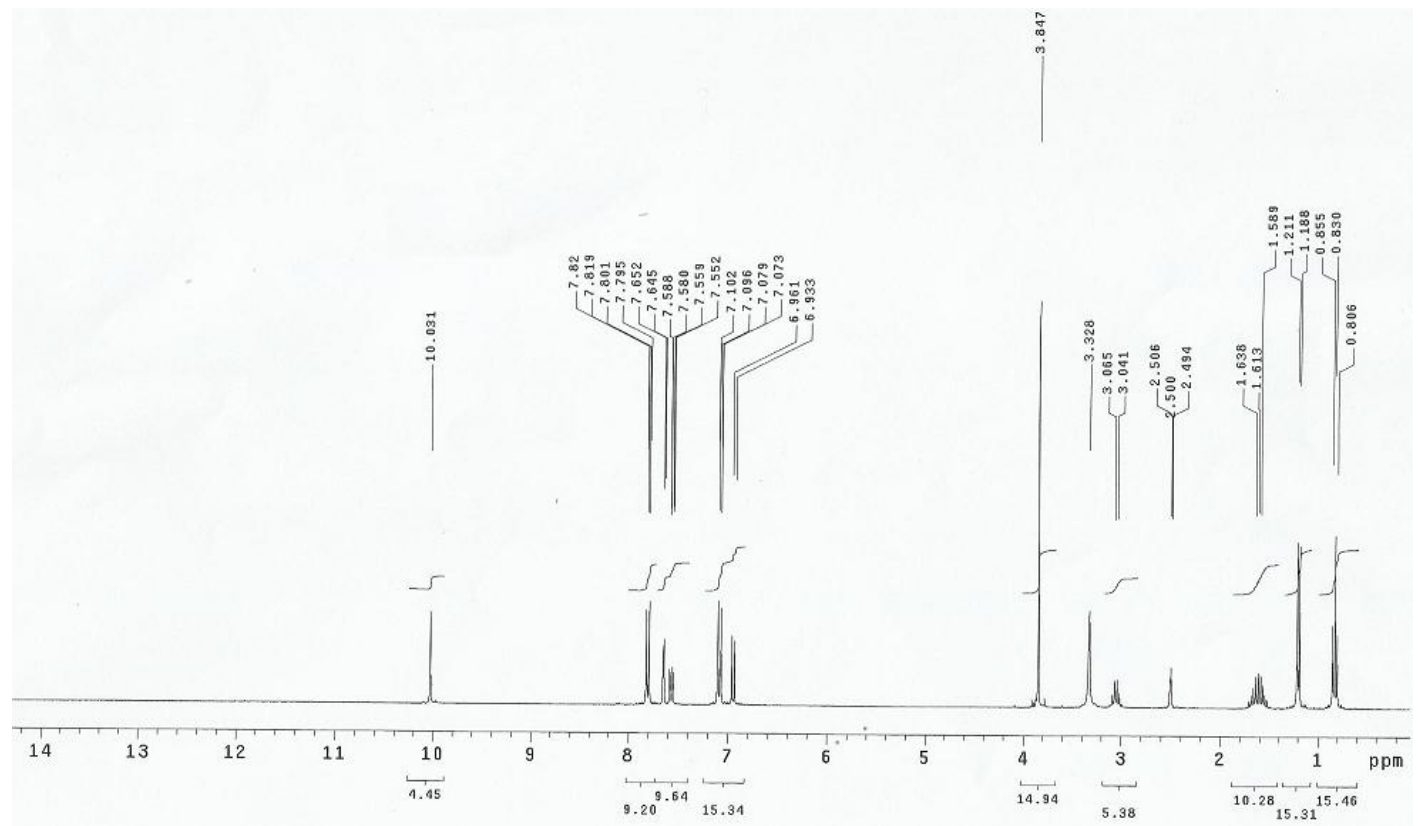

Fig. (3): ${ }^{1}$ HNMR of the prepared compound (I). 


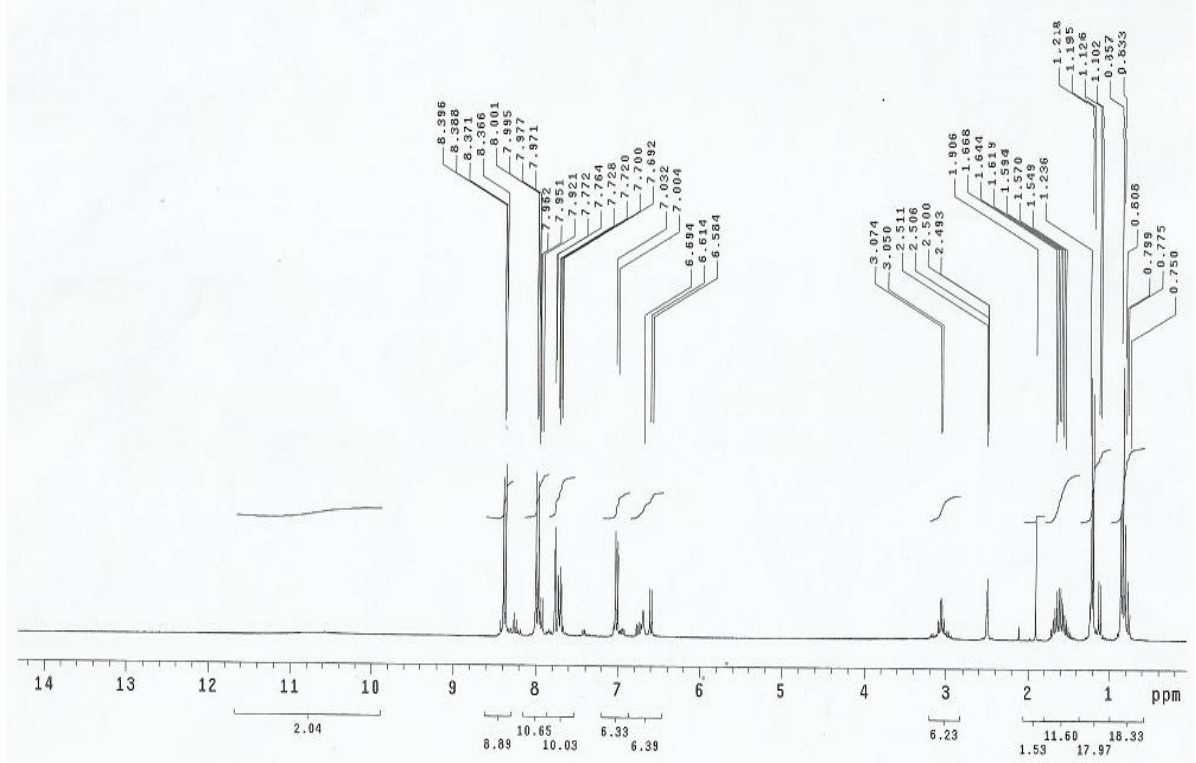

Fig. (4): ${ }^{1} \mathrm{HNMR}$ of the prepared compound (II).

Table (4) mass spectra for (I):

\begin{tabular}{|c|c|c|c|}
\hline \multicolumn{2}{|r|}{ ROULE } & \multicolumn{2}{|c|}{ ROULE B } \\
\hline $\mathbf{m} / \mathbf{z}$ & Molecular Formula & $\mathbf{m} / \mathbf{z}$ & Molecular formula \\
\hline 284 & $\left.\mathrm{C}_{17} \mathrm{H}_{20} \mathrm{~N}_{2} \mathrm{O}_{2}\right]+$ & 284 & $\left.\mathrm{C}_{17} \mathrm{H}_{20} \mathrm{~N}_{2} \mathrm{O}_{2}\right]+$ \\
\hline 227 & $\left.\mathrm{C}_{13} \mathrm{H}_{11} \mathrm{~N}_{2} \mathrm{O}_{2}\right]+$ & 253 & {$\left[\mathrm{C}_{16} \mathrm{H}_{17} \mathrm{~N}_{2} \mathrm{O}\right]+$} \\
\hline 107 & $\left.\mathrm{C}_{7} \mathrm{H}_{7} \mathrm{~N}_{2} \mathrm{O}\right]+{ }^{\circ}$ & 177 & {$\left[\mathrm{C}_{10} \mathrm{H}_{13} \mathrm{~N}_{2} \mathrm{O}\right]+$} \\
\hline 77 & C6H5]+ & 149 & {$\left[\mathrm{C}_{10} \mathrm{H}_{13} \mathrm{O}\right]+{ }^{+}$} \\
\hline & & 93 & {$\left[\mathrm{C}_{6} \mathrm{H}_{5} \mathrm{O}\right]+$} \\
\hline
\end{tabular}

Table (5): Mass spectroscopy for (II):

\begin{tabular}{|c|c|c|c|}
\hline \multicolumn{2}{|c|}{ ROULE A } & \multicolumn{2}{|c|}{ ROULE B } \\
\hline $\mathbf{m} / \mathbf{z}$ & Molecular Formula & $\mathbf{m} / \mathbf{z}$ & Molecular formula \\
\hline 299 & $\left.\mathrm{C}_{16} \mathrm{H}_{17} \mathrm{~N}_{3} \mathrm{O}_{3}\right]+$ & 299 & $\left.\mathrm{C}_{16} \mathrm{H}_{17} \mathrm{~N}_{3} \mathrm{O}_{3}\right]+$ \\
\hline 242 & $\left.\mathrm{C}_{12} \mathrm{H}_{8} \mathrm{~N}_{3} \mathrm{O}_{3}\right]+\cdot$ & 253 & $\left.\mathrm{C}_{16} \mathrm{H}_{17} \mathrm{~N}_{2} \mathrm{O}\right]+$ \\
\hline 150 & $\left.\mathrm{C}_{6} \mathrm{H}_{4} \mathrm{~N}_{3} \mathrm{O}_{2}\right]+$ & 149 & $\left.\mathrm{C}_{10} \mathrm{H}_{13} \mathrm{O}\right]+$ \\
\hline 122 & $\left.\mathrm{C}_{6} \mathrm{H}_{4} \mathrm{NO}_{2}\right]+$ & 120 & $\left.\mathrm{C}_{8} \mathrm{H}_{8} \mathrm{O}\right]+$ \\
\hline 76 & $\left.\mathrm{C}_{6} \mathrm{H}_{4}\right]+{ }^{+}$ & 92 & $\left.\mathrm{C}_{6} \mathrm{H}_{4} \mathrm{O}\right]+$ \\
\hline & & 75 & $\left.\mathrm{C}_{6} \mathrm{H}_{3}\right]+$ \\
\hline
\end{tabular}

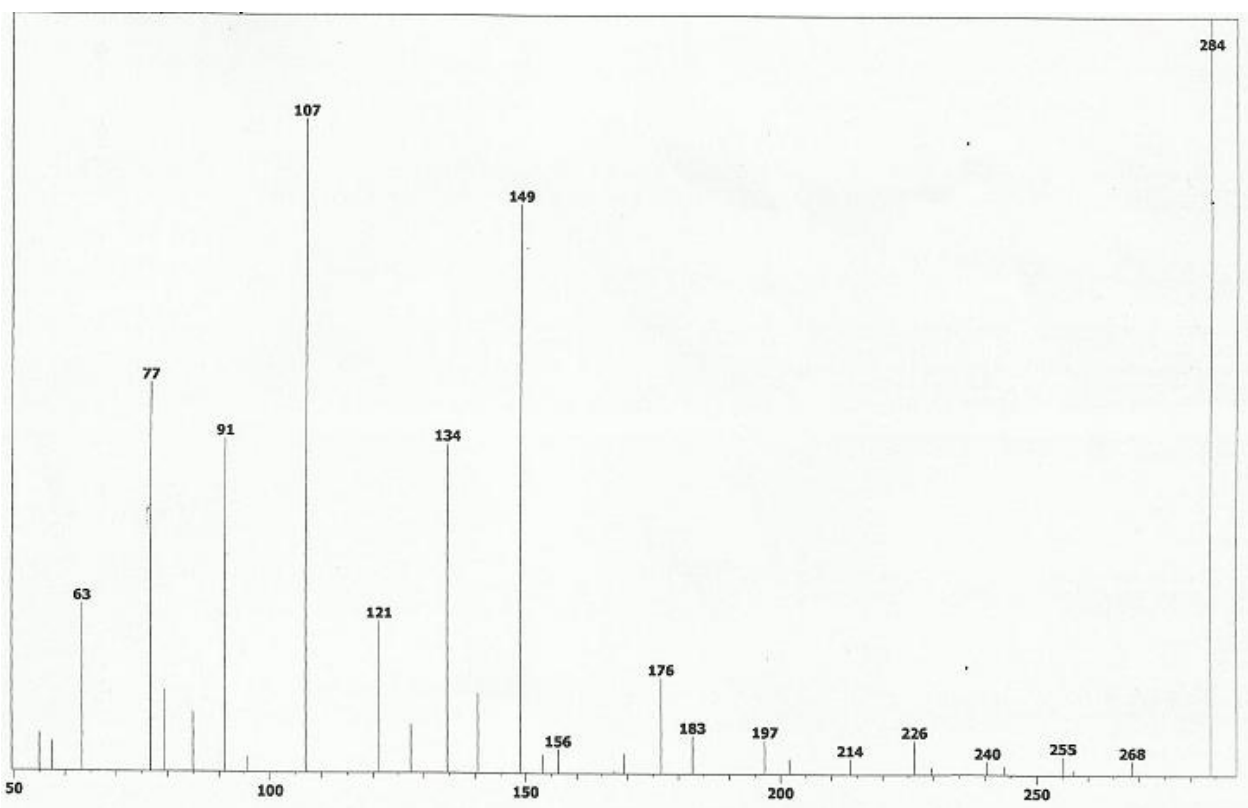

Fig. (6): Mass spectra of the prepared compound (I). 


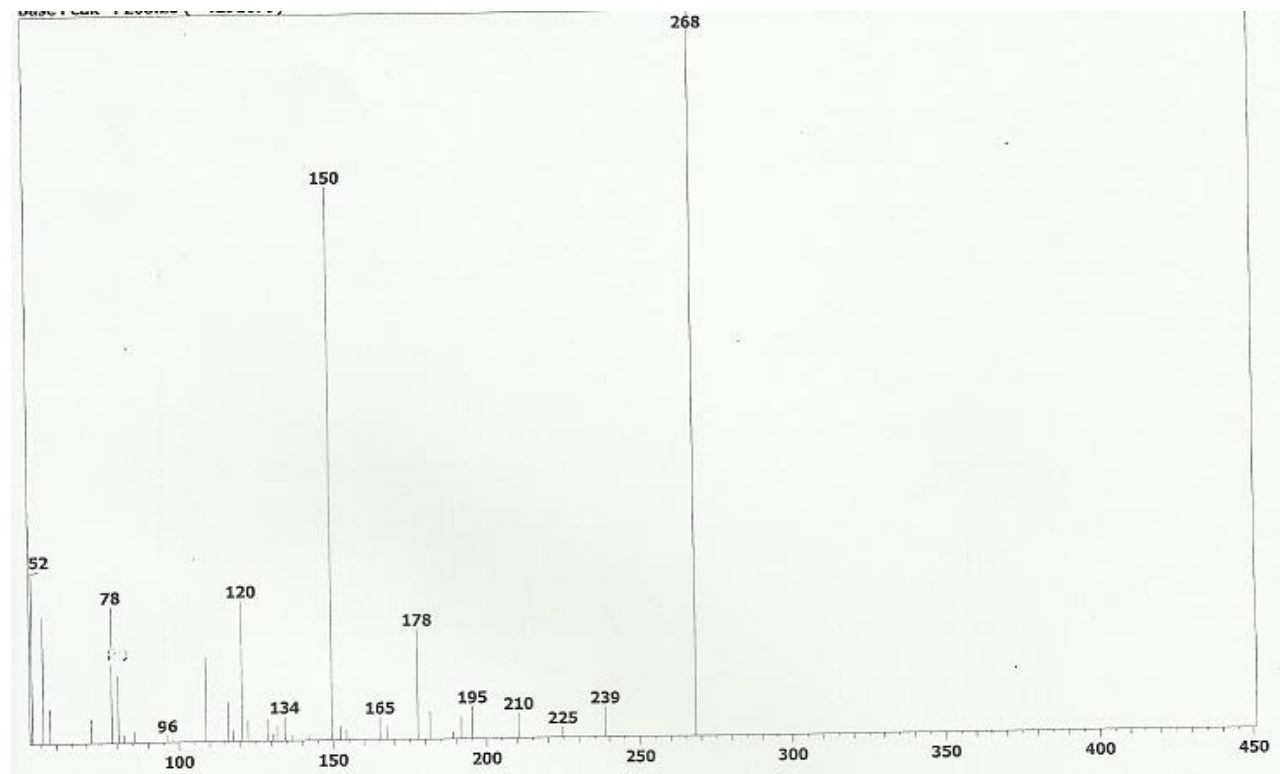

Fig. (6): Mass spectra of the prepared compound (II).

The schematic fragmentation of compounds I and II are illustrated as follows: Routs of fragmentation of I
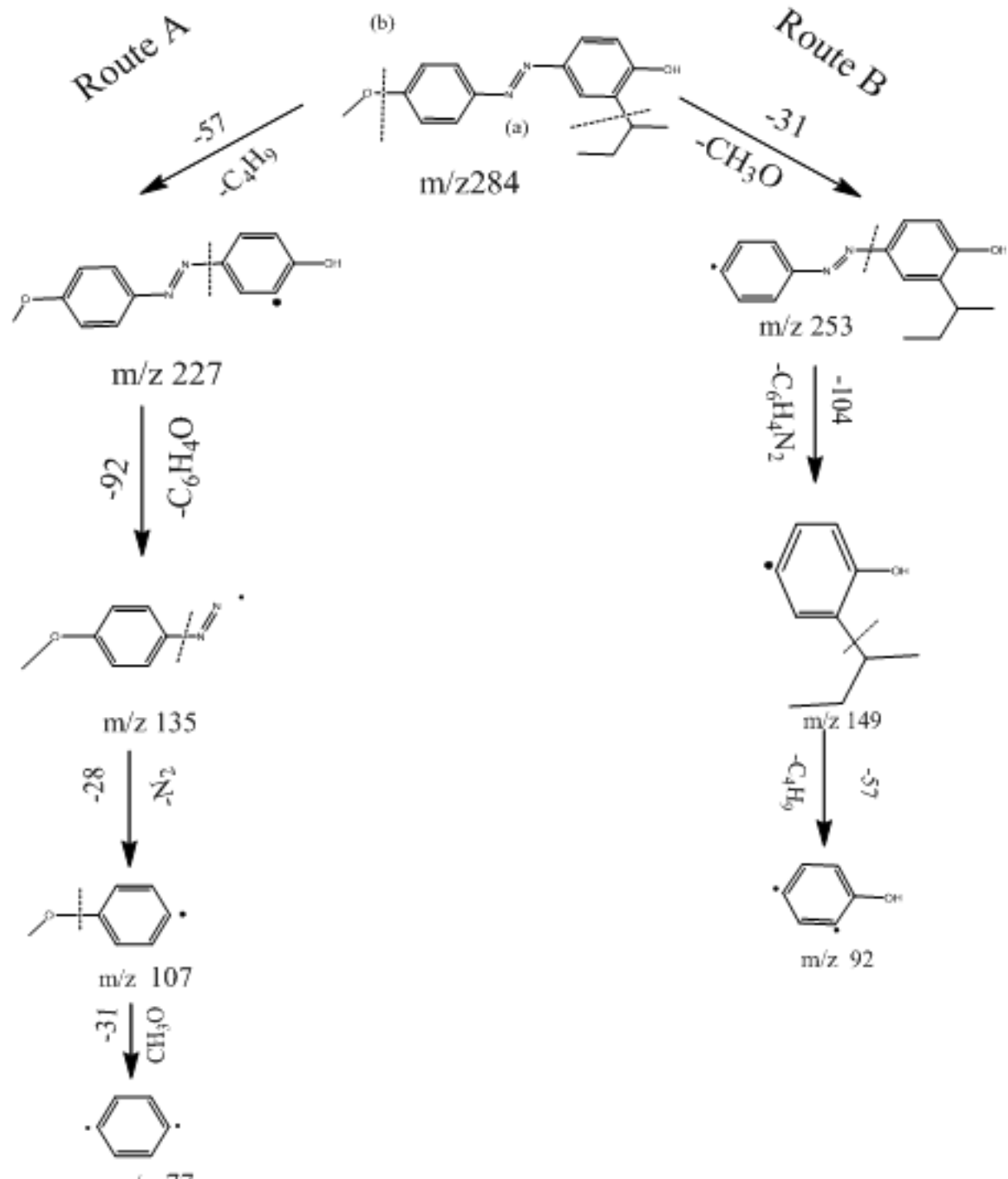

$\mathrm{m} / \mathrm{z} 77$

Scheme II 
Routs of fragmentation of II

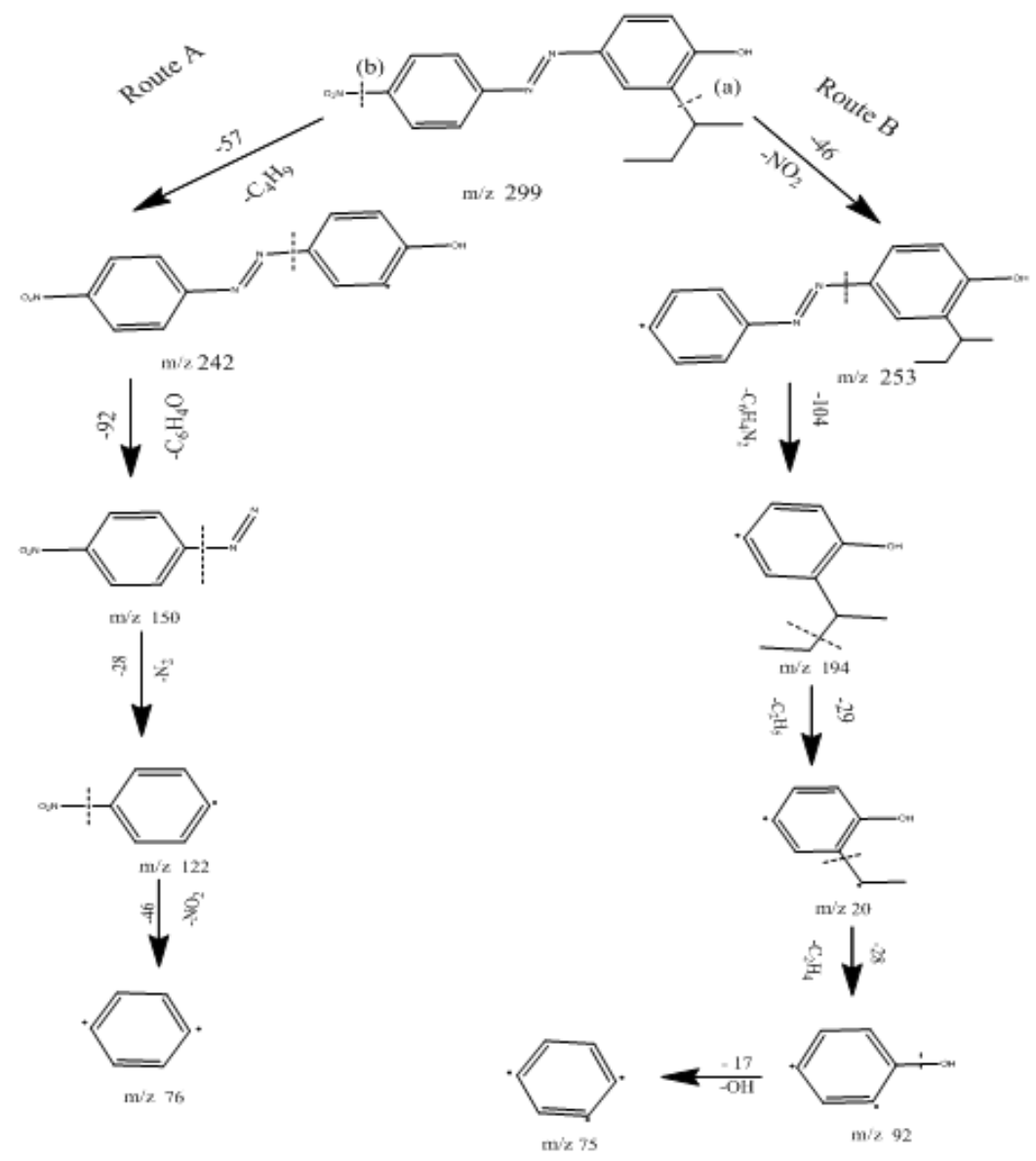

scheme III

\section{Evaluation of the synthesized compounds as antioxidants additives for base stock:}

Total Acid Number (TAN):

The prepared additives were added to local base stocks. The blend obtained were subjected to sever oxidation condition $120^{\circ} \mathrm{c}$. sample were taken at intervals of 24 hours and up 96 hours of oxidation. Usually the total acid number of the oil increases by increasing the oxidation time. The increment of TAN value is due to oxidation processes which produce peroxides. These peroxides undergo further reaction to form alcohols, aldehydes and ketones. The total acid number is affected by the formation of carboxylic acids after prolonged oxidation and increases with increasing carbonyl formation which deteriorates the lubrication ability of the oil [28-32].

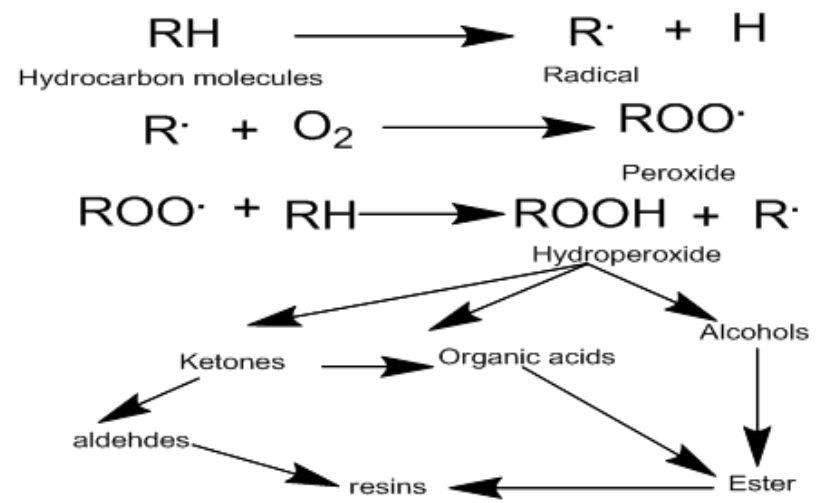

Scheme VI: Schematic Representation of Oxidation of Mineral oil.

From table (6) the total acid number increases from $0.067 \mathrm{mg} \mathrm{KOH} / \mathrm{g}$ to $2.01 \mathrm{mg} \mathrm{KOH} / \mathrm{g}$ when thermally oxidized for 96 hours 
Table (6) - Total Acid Numbers and Viscosities of the Base Stock at different Times without Additives

\begin{tabular}{|l|l|l|l|l|l|l|l|}
\hline \multicolumn{2}{|c|}{ Total Acid Numbers, mg KOH g Sample } & \multicolumn{4}{|c|}{ Vis os $i$ t c St at $40^{\circ} \mathrm{C}$} \\
\hline $24 \mathrm{hrs}$ & $48 \mathrm{hrs}$ & $72 \mathrm{hrs}$ & $96 \mathrm{hrs}$ & $24 \mathrm{hrs}$ & $48 \mathrm{hrs}$ & $72 \mathrm{hrs}$ & $96 \mathrm{hrs}$ \\
\hline 0.94 & 1.02 & 1.20 & 2.01 & 59.38 & 64.33 & 68.49 & 77.70 \\
\hline
\end{tabular}

\section{Effect of substituted alkyl additives}

In presence of additives I (with donating group), II(with drawing group), the results of the total acid numbers are given after thermal oxidation of the base oil for 24 hours, table (7). First of all, the total acid numbers decrease by increasing the additive dose from 200 part per million to 600 parts per million. Among the two azo phenols compounds I, and II, the efficiency order of these compounds towards decreasing TAN is ranked as follows II > I.

\section{Effect of additives concentration}

The data shown in Figures (1-3) represented the relation between the total acid number and the oxidation time when using the additive concentrations 200, 400 and 600 ppm. Figures (1) showed the relation between the additives concentrations (I and II) and the total acid numbers with the oxidation periods (24, 48, 72 and 96hrs). Figure- (1) (with 200 ppm.) showed that the fresh base stock oil and the compound II additive gave poor results of total acid numbers than compound I. Figure-( 2) showed that, with the concentration of $400 \mathrm{ppm}$. , the order of increasing inhibition efficiency is ranked as follows: I > II > Fresh. In case of Figure (3), with $600 \mathrm{ppm}$. Additives concentration, it is clear that there is a marked increase in the total acid number on using all the additives used and the order of increasing efficiency was as follows: I > II > Fresh sample.

Table (7): TAN x $10^{2}$ after 24 hours

\begin{tabular}{|l|l|l|}
\hline \multirow{2}{*}{ Conc. } & Total Acid Numbers, mg KOH / g Sample x $10^{2}$ \\
\cline { 2 - 3 } $200 \mathrm{ppm}$ & Compound I & Compound II \\
\hline $400 \mathrm{ppm}$ & 57 & 77 \\
\hline $600 \mathrm{ppm}$ & 37 & 50 \\
\hline
\end{tabular}

Table (8): TAN x $10^{2}$ after 48 hours

\begin{tabular}{|l|l|l|}
\hline \multirow{2}{*}{ Conc. } & \multicolumn{2}{|l|}{ Total Acid Numbers, $\mathrm{mg} \mathrm{KOH} / \mathrm{g}$ Sample $\mathrm{x} 10^{2}$} \\
\cline { 2 - 3 } & Compound I & Compound II \\
\hline $200 \mathrm{ppm}$ & 61 & 85 \\
\hline $400 \mathrm{ppm}$ & 41 & 59 \\
\hline $600 \mathrm{ppm}$ & 37 & 46 \\
\hline
\end{tabular}

Table (9): TAN x $10^{2}$ after 72 Hours

\begin{tabular}{|l|l|l|}
\hline \multirow{2}{*}{ Conc. } & \multicolumn{2}{|l|}{ total Acid Numbers, mg KOH / g Sample x $10^{2}$} \\
\cline { 2 - 3 } $200 \mathrm{ppm}$ & Compound I & Compound II \\
\hline $400 \mathrm{ppm}$ & 64 & 88 \\
\hline $600 \mathrm{ppm}$ & 56 & 67 \\
\hline
\end{tabular}

Table (10): TAN x $10^{2}$ after 96 Hours

\begin{tabular}{|l|l|l|}
\hline \multirow{2}{*}{ Conc. } & \multicolumn{2}{|l|}{ Total Acid Numbers, mg KOH / g Sample x $10^{2}$} \\
\cline { 2 - 3 } $200 \mathrm{ppm}$ & Compound I & Compound II \\
\hline $400 \mathrm{ppm}$ & 78 & 108 \\
\hline $600 \mathrm{ppm}$ & 63 & 92 \\
\hline
\end{tabular}

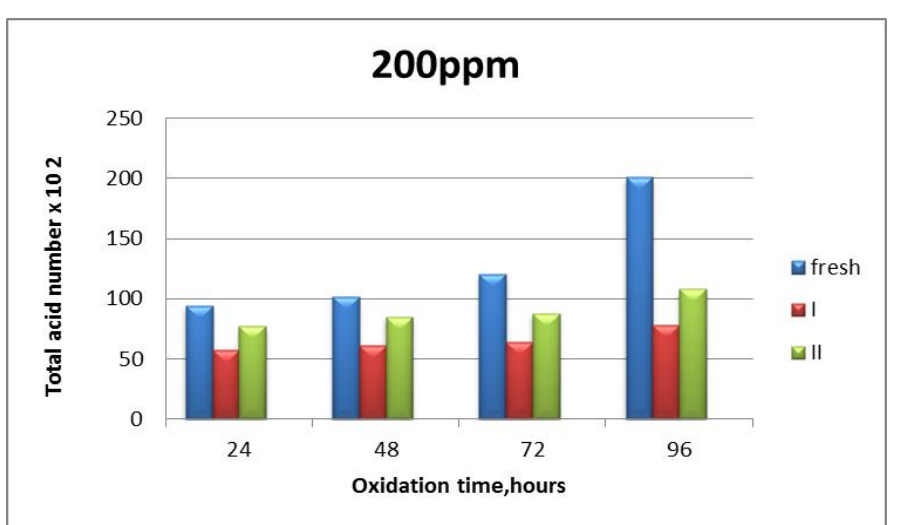

Figure 1. Variation of Total Acid Number (TAN) of base oil without and with $200 \mathrm{ppm}$ I and II additives. 


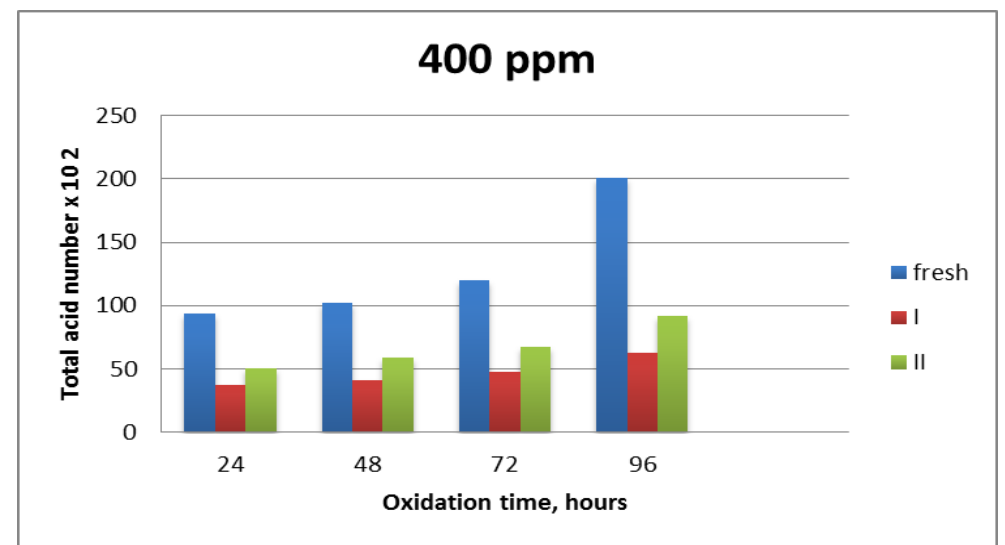

Figure 2. Variation of Total Acid Number (TAN) of base oil without and with $400 \mathrm{ppm}$ I and II additives

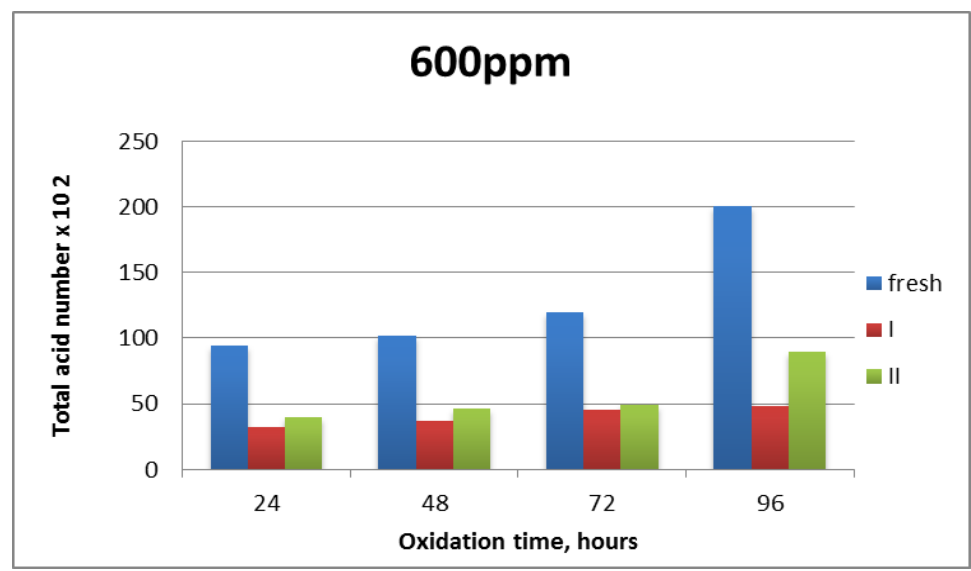

Figure (3). Variation of Total Acid Number (TAN) of base oil without and with 600 ppm I and II additives.

\section{Viscosity}

Viscosity is one of the most important properties for the characterization of lubricants and their transport properties, and it is a measure of internal friction in a fluid. In general, the viscosity of base oil increases with the operating time of oxidation. The increase in viscosity is due to the polymerization in the molecular structure. During oxidation, the oil degrades from peroxides to carboxylic acids, thus forming a long chain molecular structure. This structure can polymerize to form big molecules with significantly high viscosity indicating that heavy lubricant degradation exists. The viscosity is always decreased by the addition of additives to the oil as a result of thermal oxidation. The data of the viscosities are tabulated in Tables (11-14) and graphically represented in Figures (4-6).

Table ( 11 ): Viscosity x $10^{2}$ after 24 hours

\begin{tabular}{|l|l|l|}
\hline \multirow{2}{*}{ Conc. } & Viscosity $\mathrm{x} 10^{2}$ \\
\cline { 2 - 3 } $200 \mathrm{ppm}$ & Compound I & Compound II \\
\hline $400 \mathrm{ppm}$ & 5527 & 5730 \\
\hline $600 \mathrm{ppm}$ & 5390 & 5588 \\
\hline
\end{tabular}

Table ( 12 ): Viscosity x $10^{2}$ after 48 hours

\begin{tabular}{|l|l|l|}
\hline \multirow{2}{*}{ Conc. } & Viscosity $\mathrm{x} 10^{2}$ \\
\cline { 2 - 3 } & Compound I & Compound II \\
\hline $200 \mathrm{ppm}$ & 5611 & 5801 \\
\hline $400 \mathrm{ppm}$ & 5423 & 5590 \\
\hline $600 \mathrm{ppm}$ & 5390 & 5520 \\
\hline
\end{tabular}

Table (13): Viscosity x $10^{2}$ after 72 Hours

\begin{tabular}{|l|l|l|}
\hline \multirow{2}{*}{ Conc. } & \multicolumn{2}{|l|}{ Viscosity $\mathrm{x} 10^{2}$} \\
\cline { 2 - 3 } $200 \mathrm{ppm}$ & Compound I & Compound II \\
\hline $400 \mathrm{ppm}$ & 5680 & 5891 \\
\hline $600 \mathrm{ppm}$ & 5434 & 5745 \\
\hline
\end{tabular}


Table (14): Viscosity x $10^{2}$ after 96 Hours

\begin{tabular}{|l|l|l|}
\hline \multirow{2}{*}{ Conc. } & \multicolumn{2}{|l|}{ Viscosity $\times 10^{2}$} \\
\cline { 2 - 3 } $200 \mathrm{ppm}$ & Compound I & Compound II \\
\hline $400 \mathrm{ppm}$ & 5752 & 6450 \\
\hline $600 \mathrm{ppm}$ & 5690 & 6010 \\
\hline
\end{tabular}

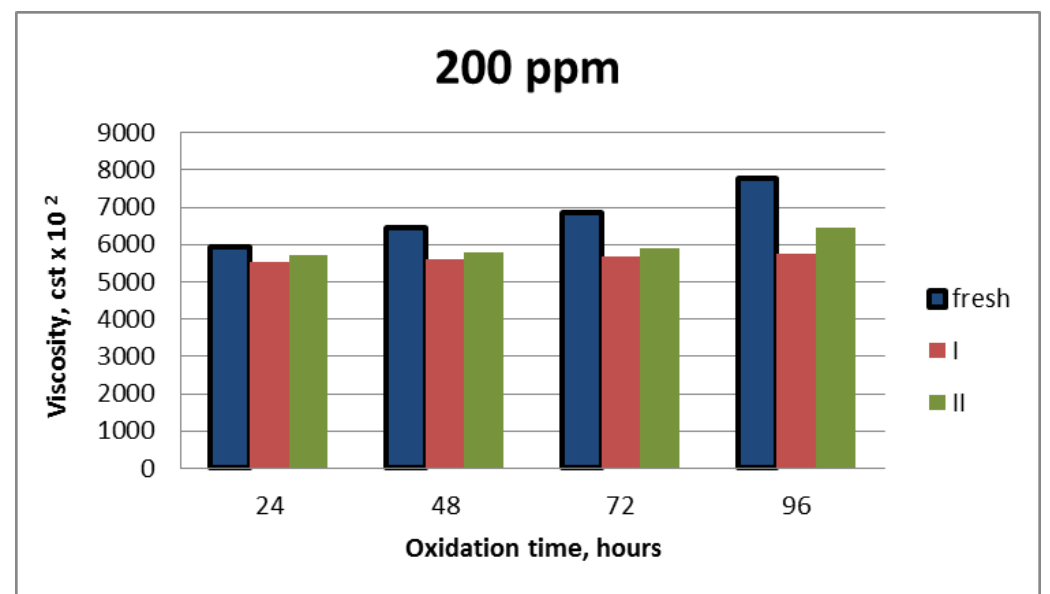

Figure 4. Variation of Viscosity of base stock without and with $200 \mathrm{ppm}$ I and II additives

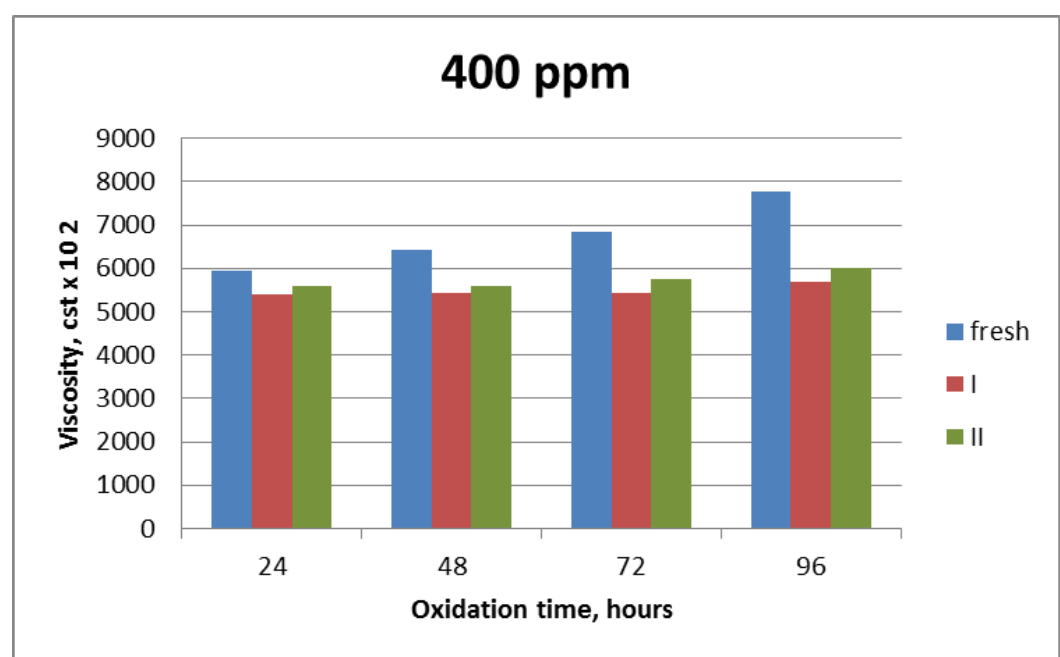

Figure 5. Variation of Viscosity of base stock without and with 400 ppm I and II additives

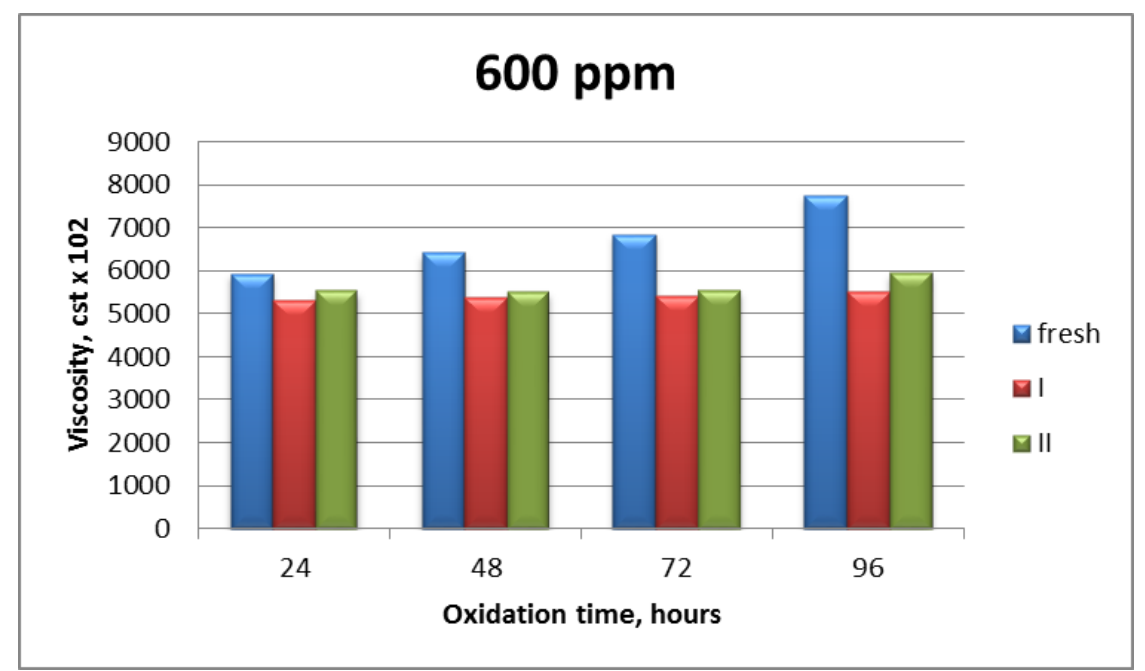

Figure 6. Variation of Viscosity of base stock without and with 600ppm I and II additives Infrared Studies 
Infrared spectroscopy (IR) is a powerful tool for investigating oil sample degradation. In general, an oil sample will form different oxygen-containing compounds at different oxidative stages. IR was therefore used to monitor the changes in oxygen-containing functional groups in response to high temperature, in order to determine the thermal oxidative mechanism for the lube base oil sample [33]. The degree of degradation upon exposure to oxidation was monitored by changes in the structure (FTIR). Oxidative degradation led to generation of carbonyl groups in oxidation products. Carbonyl peak Index (CPI) was used to characterize the degree of oxidation of the studied oil. . These have been calculated by the baseline method [34]. Tables (15-18) show the values of the carbonyl peak index of the studied oil samples.

Table (15): Base oil without and with different concentration after 24 hours

\begin{tabular}{|l|l|l|l|}
\hline \multirow{2}{*}{ Conc. } & \multicolumn{3}{|l|}{ Carbonyl peak index } \\
\cline { 3 - 4 } & Fresh oil & Compound I & Compound II \\
\hline \multirow{4}{*}{$200 \mathrm{ppm}$} & 0.40 & 0.55 \\
\cline { 3 - 4 } $400 \mathrm{ppm}$ & \multirow{8}{*}{} & 0.26 & 0.37 \\
\cline { 3 - 4 } & 0.23 & 0.33 \\
\hline
\end{tabular}

Table (16): Base oil without and with different concentration after 48 hours

\begin{tabular}{|c|c|c|c|}
\hline \multirow[b]{2}{*}{ Conc. } & \multicolumn{3}{|c|}{ Carbonyl peak index } \\
\hline & Fresh oil & Compound I & Compound II \\
\hline $200 \mathrm{ppm}$ & \multirow{3}{*}{$\stackrel{n}{2}$} & 0.43 & 0.61 \\
\hline $400 \mathrm{ppm}$ & & 0.29 & 0.44 \\
\hline 600ppm & & 0.23 & 0.33 \\
\hline
\end{tabular}

Table (17):Base oil without and with different concentration after 72 hours

\begin{tabular}{|l|l|l|l|}
\hline \multirow{4}{*}{ Conc. } & \multicolumn{4}{|l|}{ Carbonyl peak index } \\
\cline { 3 - 4 } \cline { 3 - 4 } & Fresh oil & Compound I & Compound II \\
\hline \multirow{4}{*}{$200 \mathrm{ppm}$} & $\infty$ & 0.45 & 0.65 \\
\cline { 3 - 4 } & $\infty 00 \mathrm{ppm}$ & 0.34 & 0.50 \\
\hline $600 \mathrm{ppm}$ & $\infty$ & 0.32 & 0.36 \\
\hline
\end{tabular}

Table ( 18 ):Base oil without and with different concentration after 96 hours

\begin{tabular}{|l|l|l|l|}
\hline \multirow{2}{*}{ Conc. } & \multicolumn{3}{|l|}{ Carbonyl peak index } \\
\cline { 2 - 4 } & Fresh oil & Compound I & Compound II \\
\hline $200 \mathrm{ppm}$ & \multirow{4}{*}{} & 0.58 & 0.78 \\
\hline $400 \mathrm{ppm}$ & \multirow{2}{-}{} & 0.45 & 0.68 \\
\hline $600 \mathrm{ppm}$ & 0.35 & 0.62 \\
\hline
\end{tabular}

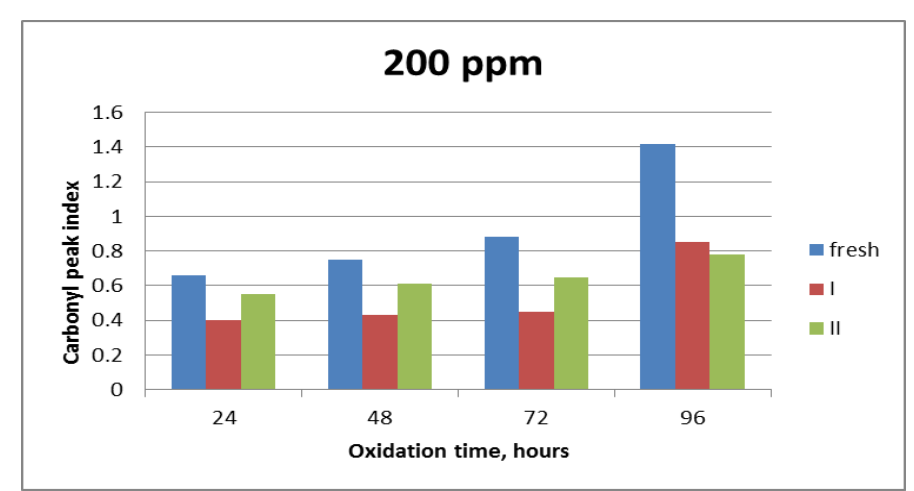

Figure.7. Variation of carbonyl peak index base stock without and with $200 \mathrm{ppm}$ I and II additives

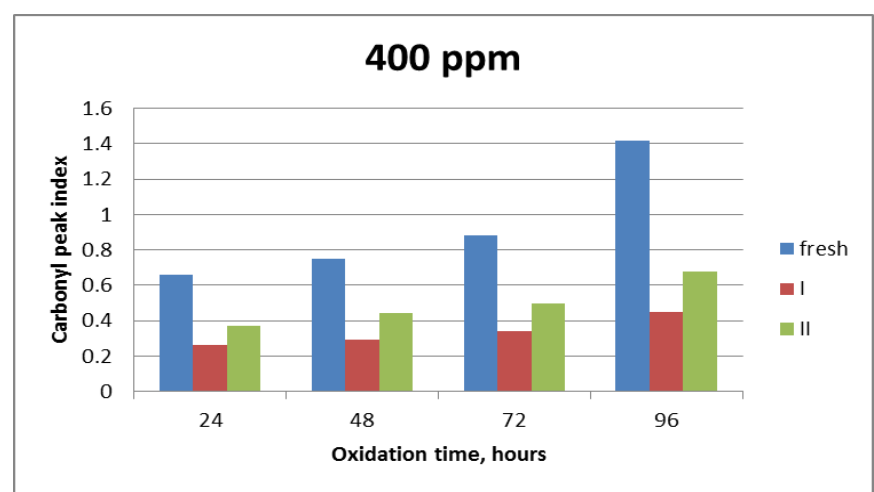

Figure.8. Variation of carbonyl peak index base stock without and with $400 \mathrm{ppm}$ I and II additives 


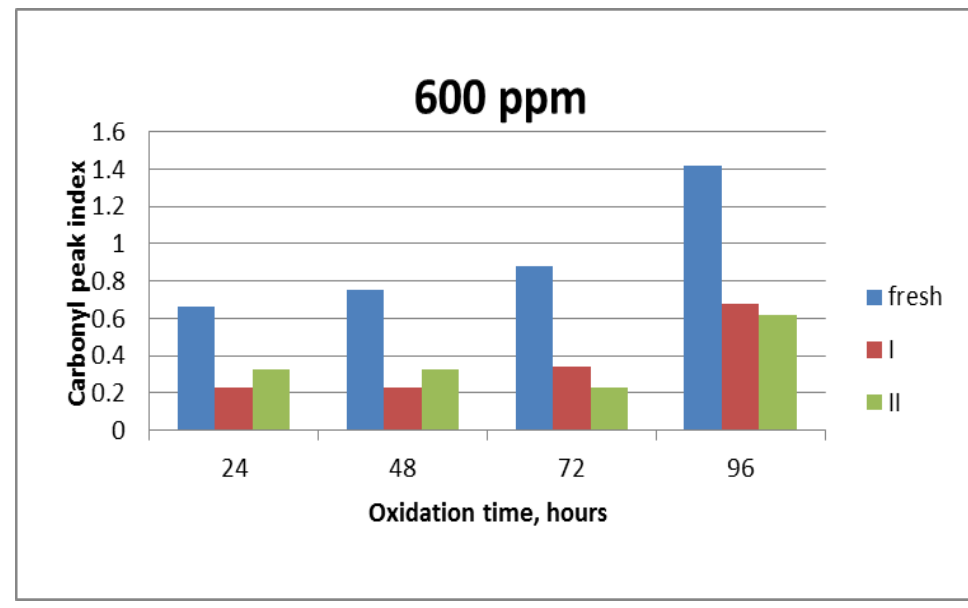

Figure.9. Variation of carbonyl peak index base stock without and with 600ppm I and II additives

Plotting the area of the carbonyl peak index appearing in the FT-IR spectra as a function of the oxidation time has already been demonstrated to provide an insight into the oxidation kinetics of hydrocarbons and into the effect of lubricant additives on the oxidation of base stocks [35]. Fig (7,8 and 9) shows the changes of CPI as a function of oxidation time.It was observed that once oxidation of the base oil carbony 1 formation accelerated and the carbonyl index values of the oils are shown to increase with the oxidation time. As the additive concentration was increased, carbonyl absorption decreased, indicating oxidation inhibition by the additive.

\section{Correlation of the antioxidant character of the heterocyclic additives with their structures}

Using the Ab initio (HF/3-21G) and semiempirical (AM1, MNDO and PM3) methods of calculations by Chem Bio Draw Ultra 12 software, the Huckel and Mulliken charges, the dipole moments, EHOMO (the highest occupied molecular orbital) and ELUMO (the lowest unoccupied molecular orbital) values were calculated. The charges representative atoms and other relevant quantum parameters were listed in Tables 14 and 15. The optimized structure of the molecules and the electric/orbital density distributions of HOMO and LUMO illustrated in Fig.5 and Fig.7 respectively.Mulliken population analysis is mostly used for the calculation of the charge distribution in a molecule [36]. These numerical quantities are easy to obtain and they provide at least a qualitative understanding of the structure and reactivity of molecules [37]. The dipole moment is another indicator of the electronic distribution in a molecule. It is one of the properties used to discuss and to rationalize the structure [38]. No significant relationship has been found between the dipole moment values and inhibition efficiencies. Besides, there is a lack of agreement in the literatures on the correlation between the dipole moment and inhibition efficiency [39-40]. Highest occupied molecular orbital energy $\left(\mathrm{E}_{\text {Hомо }}\right)$ and lowest unoccupied molecular orbital energy $\left(\mathrm{E}_{\mathrm{LUMO}}\right)$ are very popular quantum chemical parameters. These orbitals, also called the frontier orbitals, determine the way the molecule interacts with other species. The HOMO is the orbital that could act as an electron donor, since it is the outermost (highest energy) orbital containing electrons. The LUMO is the orbital that could act as the electron acceptor, since it is the innermost (lowest energy) orbital that has room to accept electrons. According to the frontier molecular orbital theory, the formation of a transition state is due to an interaction between the frontier orbitals (HOMO and LUMO) of reactants [41].

Table (19) Quantum chemical parameters of I

\begin{tabular}{|l|l|l|}
\hline \multicolumn{1}{|c|}{ Quantum parameters } & $\mathrm{HF}(3-21 \mathrm{G})$ & MNDO \\
\hline$E_{\text {HOMO }}(\mathrm{eV})$ & -4.122 & -4.122 \\
\hline$E_{\text {LUMO }}(\mathrm{eV})$ & -2.203 & -2.204 \\
\hline$E_{\text {LUMO-HOMO }}(\mathrm{eV})$ & 1.919 & 1.918 \\
\hline Huckel charge $(\mathrm{eV})$ & $\mathrm{N}_{9}=0.428$ & $\mathrm{~N}_{9}=0.428$ \\
& $\mathrm{~N}_{10}=0.425$ & $\mathrm{~N}_{10}=0.425$ \\
\hline Mulliken charge $(\mathrm{eV})$ & $\mathrm{N}_{9}=-0.51$ & $\mathrm{~N}_{9}=-0.113$ \\
& $\mathrm{~N}_{10}=-0.51$ & $\mathrm{~N}_{10}=-0.120$ \\
\hline$\mu$ (Debye) & 2.9 & 2.27 \\
\hline
\end{tabular}

Table (20) Quantum chemical parameters of II

\begin{tabular}{|l|l|l|}
\hline \multicolumn{1}{|c|}{ Quantum parameters } & $\mathrm{HF}(3-21 \mathrm{G})$ & $\mathrm{MNDO}$ \\
\hline$E_{\text {HOMO }}(\mathrm{eV})$ & -6.295 & -6.297 \\
\hline$E_{\text {LUMO }}(\mathrm{eV})$ & -2.195 & -2.193 \\
\hline$E_{\text {LUMO-HOMO }}(\mathrm{eV})$ & 4.100 & 4.104 \\
\hline Huckel charge $(\mathrm{eV})$ & $\mathrm{N}_{7}=1.109$ & $\mathrm{~N}_{7}=1.01$ \\
\hline
\end{tabular}




\begin{tabular}{|l|l|l|}
\hline & $\mathrm{N}_{8}=0.619$ & $\mathrm{~N}_{8}=0.693$ \\
& $\mathrm{~N}_{9}=0.558$ & $\mathrm{~N}_{9}=0.553$ \\
\hline Mulliken charge (eV) & $\mathrm{N}_{7}=0.27$ & $\mathrm{~N}_{7}=0.429$ \\
& $\mathrm{~N}_{8}=-0.39$ & $\mathrm{~N}_{8}=-0.164$ \\
& $\mathrm{~N}_{9}=-0.36$ & $\mathrm{~N}_{9}=-0.045$ \\
\hline$\mu$ (Debye) & 7.64 & 6.79 \\
\hline
\end{tabular}

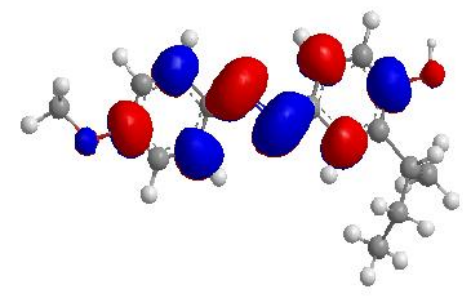

HOMO

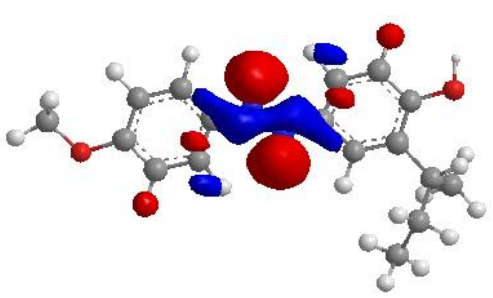

LUMO

Figure (10): The frontier molecule orbital density distributions of (I)

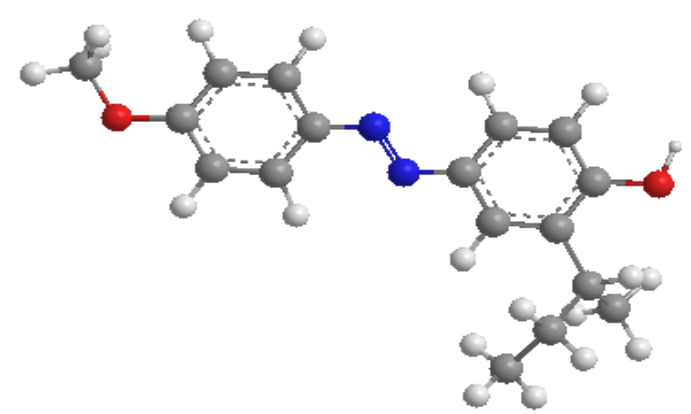

Figure (11): Optimized structure of (I)

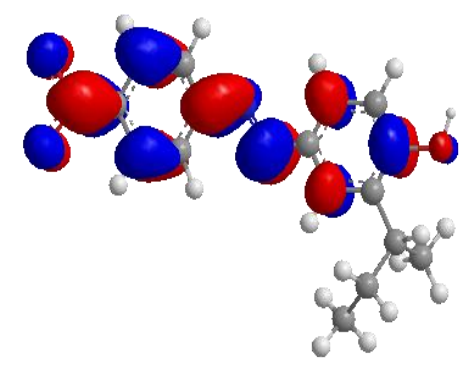

HOMO

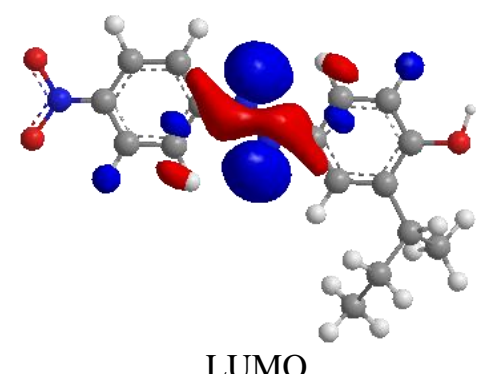

LUMO

Figure (12): The frontier molecule orbital density distributions of (II)

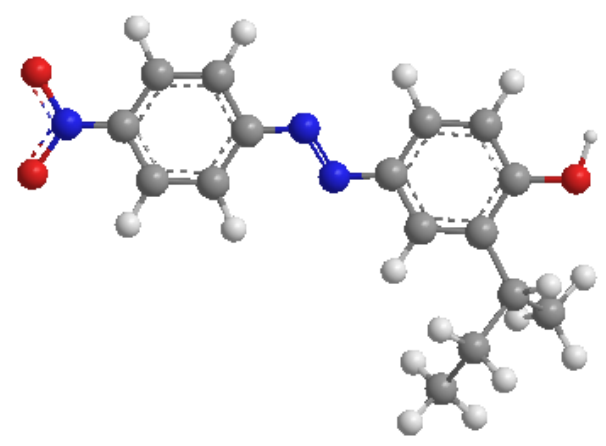

Figure (13): Optimized structure of (II)

From Tables 14 and 15 it is found that the $E_{\text {Hомо }}$ and the $E_{\mathrm{LUMO}}$ changed rulelessly, while the energy gap $E_{\mathrm{LUMO}}-E_{\text {Номо; }}$ the difference in energy between the $E_{\text {Номо }}$ and $E_{\mathrm{LUMO}}$ decreased with increasing the inhibition efficiency. The energy gap $(\Delta E)$ is an important stability index [42]. A large HOMO-LUMO gap implies high stability for the molecule in chemical reactions [43]. The values of $(\Delta E)$ indicate remarkably that the smaller energy gap results in a high oxidation inhibition, reflecting the stronger interaction between the inhibitors and metal surface. The interactions are probably physical adsorption [44-45]. 


\section{Conclusion}

The results obtained in this work, indicate the following:

- Increasing the oxidation time, always increase both of the total acid number, the viscosity and intensity of carbonyl group. Some organic synthesized additives proved to be successful in controlling the oxidation stability of the base stock. The oxidation inhibition efficiency of these compounds depends. We noticed for compound (I), with donating group, has more efficiency than compound (II).

- The data reveals that the most effective concentration in case of (600 ppm).

- The results show that, by using the quantum chemical calculations (Ab initio $\{\mathrm{HF} / 3-21 \mathrm{G}\}$ and the semiemperical gas phase AM1 \{Austin model 1\}), the compounds with low energy gap ( $\square$ E) have good inhibition efficiencies which are in good agreement with the practical results.

\section{References}

[1] BBhushan, Principles and Applications of Tribology (Wiley, New York, 1999).

[2] B. Bhushan, Introduction to Tribology (Wiley, New York, 2002).

[3] K.C. Ludema, Friction, Wear, Lubrication: A Text Book in Tribology (CRC Press, New York,1996).

[4] Frederique Haus, Olivier Boissel, Guy-Alain Junter,Chemosphere 50 (2003) 939-948.

[5] Allison, J.P.(Ed). "Criteria for quality of petroleum products", Applied Science: Barking, 1973, Chapter 10.

[6] Allyson M. Barnes, Keith D. Bartle, Vincent R.A. Thibon; Tribology international, 34,389-395(2001).

[7] Vamos E.; Temporary corrosion preventation, Technical Publishing Co. Budapest(1978).

[8] Stefan Korcek; Mllton D. Johnson, Ronald K. Jensen, and Mlklo Zlnbo Ind. Eng. Chem. Prod. Res. Dev. 1986, 25, 621-627.

[9] K.D. Breese, J.-F. LameÁthe, C. DeArmitt, Polymer Degradation and Stability 70 (2000) 89-96.

[10] Lucedio Greci, Alexander Mar'in,f Pierluigi Stipa \& Patricia Carloni, Polymer Degradation and StabilUy 50 (1995) $305-312$.

[11] Guanqiu Shen; Zhi Zheng, Yong Wan; Xiangdong Xua, Lili Caoa, Qixia Yue, Tianjian Sunb, Airou Liu ,Wear 246 (2000) 55-58.

[12] Junyan Zhang, Weimin Liu, Qunji Xue,Wear 231_1999. 65-70.

[13] Milton, Frankel, Tarzana; Joseph E. Flanagan, US Patent,4303414 (1981)

[14] Charles J. Pedersen, Penns Grove,n.j., assignor,US Patent, 461632(1942).

[15] 15E. Kraka and D. Cremer; " Computer design of anticancer drugs", J. Am.Chem.

[16] Soc. 122, 8245-8264, 2000

[17] M. Karelson and V. Lobanov;" Quantum chemical descriptors in QSAR/QSPR

[18] Studies" , Chem. Rev. , 96 , 1027-1043,1996. Hinchliffe;" Modelling Molecular Structures", John Wiley \& Sons, New York, 1994.Hinchliffe;" Chemical Modelling From Atoms to Liquids", John Wiley \& Sons,New York, 1999.

[19] 19M. Bouayed, H. Rabaa, A. Srhiri, J.Y. Saillard and A. B. Bachir; "Experimental andtheoretical study of organic corrosion inhibitors on iron in acidic medium", Corros. Sci., 41, 501-517, 1999.

[20] 20M.A. Quraishi and R. Sardar;" Corrosion inhibition of mild steel in acid solutions by some aromatic oxadiazoles", Mater. Chem. Phys., 78, 425-431, 2002.

[21] 21 E. Stupnišek-Lisac, S. Podbršč̌ek and T. Soric';" Non-toxic organic zinc corrosion inhibitors in hydrochloric acid, J. Appl. Electrochem., 24, 779-784, 1994.

[22] 22F. Touhami, A. Aouniti, Y. Abed, B. Hammouti, S. Kertit, A. Ramdani and K. Elkacemi;" Corrosion inhibition of Armco iron in $1 \mathrm{M} \mathrm{HCl}$ media by new bipyrazolic derivatives", Corros. Sci., 42 , 929-940, 2000.

[23] 23 L. Tang, X. Li, L. Li, G. Mu and G. Liu;" Interfacial behavior of 4-(2-pyridylazo) resorcin between steel and hydrochloric acid", Surf. Coat. Technol., 201,384-388, 2006.

[24] 24M. Hosseini, S.F.L. Mertens, M. Ghorbani and M.R. Arshadi;" Asymmetrical Schiff Bases as inhibitors of mild steel corrosion in sulphuric acid media", Mater. Chem. Phys., 78, 800-808, 2003.

[25] 25 N.C.Subramanyam,B.S.SheshardiandS.A.Mayanna;"Thioureaand substitutedthioureas as corrosion inhibitors for aluminium in sodium nitrite solution", Corros. Sci. 34, 563-571, 1993.

[26] 26J. TRZASKA and Z. GALEWSKI,OPTO-ELECTRONICS REVIEW 17(2), 129-139 (2009).

[27] 27 Craig L. Hiilemann,'a Gerald R. Van Hecke,. and (In part) S. Robert Peak, John B. Winther,lb Martin A. Rudat,lb David A. Kalman, lb and Martha L. White, The Journal of Physlcal Chemistry, Vol. 79, No. 15(1975).

[28] 28H.M.Hassan; Indian J. Technol., 5, 343 - 345, 1998

[29] 29H.M.Hassan, M.M.Youssif, A.M. Khalil and E.H.E.Youssif; J. Synth. Lubrication, 17 (1), 55 - 69, 2000

[30] 30 A.R.Maria, E.Selma, J.O.B. Carioca and G.G.Barros; Fuel, 86 (15), 2416 - 2421, 2007.

[31] 31 R.Q.Aucelio, R.M.Souza, R.C.Campos and P. S. Miekeley; Spectrochimica Acta Part B, 62, 952 - 961, 2007.

[32] 32 A.Suzuki, R.Ulfiati and M.Masuko; Tribology International, 24 (6), 987-994, 2009.

[33] 33Ozen, B. F., Mauer, L. J., J. Agric. Food Chem, 50, 3898-901 (2002).

[34] 34Prieri F, GresserE, LeDre'au Y, ObiolsJ, Kister, Jr. Applied Spectroscopy; 62(7):810-6,(2008).

[35] 35 Pavia, D. L., LAMPMAN, G. M., KRIZ, G. S. Introduction to Spectroscopy. New York: Harcourt Brace College Publishers.pp. 510, (1997).

[36] 36J.N. Murrell, S.F. Kettle, J.M. Tedder, The Chemical Bond, John Wiley \& Sons, Chichester, 1985.

[37] 37C. Gruber, V. Buss, Chemosphere, 19,1595 (1989).

[38] 38 O.Kikuchi; Struct. Act.Relat. 6, 179-184, 1987.

[39] 39 G.Gao and C. liang; Electrochim. Acta, 52, 4554-4559, 2007.

[40] 40N. Khalil; Electrochim.Acta, 48, 2635-2640, 2003

[41] 41 K. Fukui, Theory of Orientation and Stereoselection, Springer-Verlag, New York, (1975).

[42] 42 D.F.V. Lewis, C. Ioannides, D.V. Parke, , Xenobiotica, 24,401 (1994).

[43] 43Z. Zhou, R.G. Parr, J. Am. Chem. Soc. ,112, 5720 (1990)

[44] 44I. Lukovits, K. Palfi, E. Kalman, Corrosion 53, 915 (1997).

[45] 45 M. O” zcan, 'I. Dehri, Prog. Org. Coat. 51, 181 (2004). 